\title{
Building a Restorative University
}

\author{
Lindsey Pointer \\ $\mathrm{PhD}$ Candidate \\ Victoria University of Wellington
}

\begin{abstract}
This paper examines the progress of Victoria University of Wellington towards becoming a Restorative University. Both reactive measures, including restorative justice as a response to conflicts and rule violations, and proactive measures, including the circle process as a way to build a positive culture rooted in restorative principles, are discussed. The article suggests that Victoria University has developed a framework for building a restorative community that can be adopted in other universities.
\end{abstract}

\section{Introduction}

During recent years, Victoria University of Wellington has taken great strides as a leader in the restorative justice field. In 2013, the Diana Unwin Chair in Restorative Justice was established and Professor Chris Marshall was appointed as the inaugural holder of the Chair. The intention of the Chair is to serve as 'the focus for collaborative interdisciplinary research and teaching on restorative justice theory and practice, both within the justice sector and beyond' (Diana Unwin Chair in Restorative Justice). The influence of the Chair has been far reaching, providing insight and leadership for public sector agencies and civil society organisations. The Chair has also had a large impact on the operations of the university, moving the campus community towards a more restorative way of operating.

The vision of the Chair of Restorative Justice and other restorative justice proponents on campus is to work towards building a Restorative University; a community in which every member is valued and feels they belong, where all contribute to the common good, and where conflict is handled in ways that promote accountability and repair. A Restorative University community fosters positive relationships founded on mutual care, respect, equality, responsibility and honest communication.

When conflicts or incidents of rule breaking occur, a restorative justice process is used as a first response. Through this process, those involved in the episode meet together, with the help of a facilitator, to discuss:

- What happened?

- Who has been affected?

- What can be done to make things right?

- What can be learned for the future?

A restorative process requires the students responsible for the harm to accept responsibility for their actions and to make amends, and provides the harmed parties with a clear voice in the process. The group works together to reach an agreement about what must be done to repair the harms and restore relationships.

In addition to implementing restorative justice on campus, members of the university have embraced the vision of a Restorative University and have begun to take steps to implement restorative practices for positive, proactive culture building. The implementation of these practices has been met with enthusiasm by both staff and students. 


\section{From restorative justice to a restorative society}

The restorative justice movement began as an effort at criminal justice reform, shifting towards a more relational and community-centred method of responding to crime. Following the success of the first restorative justice programs, the practice quickly expanded both geographically and in application. By the early 1990s, restorative justice had extended to schools. In the context of schools, the word 'justice' began to be replaced by 'practices' or 'approaches' (Marshall, 2016). Similarly, designations such as 'victim' and 'offender' were considered inappropriate and were eventually replaced with labels such as 'the person harmed' and 'the person who caused the harm.' These shifts mirrored the expansion of the sorts of conflicts and wrongdoings restorative practices were used to respond to, moving beyond issues of criminal concern to a wider array of behaviour issues.

The use of restorative practices also quickly expanded from a solely reactive function, implemented as an alternative disciplinary measure, to a proactive function focused on relationship-building, conflict-resolution skills and fostering feelings of belonging. This extension of restorative practices to a proactive, culture-change function in the schools has provided a model for other organisations and civil society more broadly of how to function more restoratively (Marshall, 2016).

Out of this expansion, the vision of a 'restorative society' has emerged. This vision has grown from the idea that 'restorative justice must be perceived as a social movement dedicated to making restorative practices integral to everyday life' (Wachtel \& McCold, 2001, p. 129). In this view, the implementation of restorative justice within the criminal justice system and schools was only the beginning.

Restorative justice is more than just a novel approach to crime control or a new set of victim-sensitive justice practices; it is the tip of a very large iceberg, a project aimed at the creation of interpersonal relationships and societal institutions that foster human dignity, equality, freedom, mutual respect, democratic engagement and collaborative governance (Marshall, 2016).

Restorative principles are able to impact entire cultures and move families, schools, and communities towards more restorative ways of interacting (Braithwaite \& Strang, 2001). This restorative social movement, as it is best understood, provides a meta-concept that emphasizes restoring and building positive relationships (Boston, 2007).

The restorative social movement calls for a widespread use of restorative practices that build relationships, provide a sense of fairness and justice, and facilitate healing. Central to this vision is the facilitation of human connection. This striving for connection is at the root of what it means to be human. As Chris Marshall notes, 'Deeply encoded in our DNA as social beings is the need to belong in responsible and joyful community with others, to participate in relationships of mutual care and responsibility, from which we acquire our sense of individual identity, self-worth and meaning. We are hard wired to connect' (Marshall, 2016). The notion of a restorative society furthermore resonates with the universal desire for wholeness, healing, reconciliation and peace (Boston, 2007).

In order to create a restorative society, restorative practitioners must find ways for the experience of connection present in the restorative justice conference to be experienced apart from as a response to an incident of harm. Practices such as the 'circle' have arisen to fulfil this need. Circles are widely used in schools and increasingly in universities, workplaces and other institutions as a way to build connections, make decisions, support or reintegrate community members, and heal after hardship (Marshall, 2016). Leading circle practitioners Kay Pranis and Carolyn Boyes-Watson give the following definition of the circle process. 
The Circle is a highly structured intentional space designed to promote connection, understanding and dialogue in a group. The Circle is a powerful tool for that basic community function of working out how we are going to be together, which includes building relationships, establishing norms, and working through differences. The Circle fulfills that basic community function: it holds a healthy balance between individual needs and group needs (Pranis \& Boyes-Watson, 2015, p. 23).

Through the introduction of the circle process, communities have a clear tool that can be used to intentionally move the group towards more restorative ways of interacting.

A restorative society therefore is one in which restorative practices are used both reactively to respond to wrongdoing, and proactively to facilitate deeper connection through processes such as the circle. Through the implementation of both proactive and reactive restorative practices, the community achieves significant culture change.

\section{Restorative university}

While restorative justice migrated into schools quite early, it has just recently made its way into the university context. Increasingly, restorative justice is being used as a response to discipline issues on university campuses with encouraging results. Research by sociologists David Karp and Casey Sacks has shown that compared to the traditional conduct model, restorative practices result in fewer appeals, less serious reoffending, higher participant satisfaction, and improvement in student learning (Karp \& Sacks, 2014).

Victoria University of Wellington has also seen positive results following the implementation of restorative justice to handle incidents of student misconduct. The university began accepting referrals of student misconduct cases from Residential Life in February 2016 and since then, the support and enthusiasm for the process have grown. Through the use of restorative justice, the university has been able to avoid suspensions, expulsions, and the eviction of students from university housing and has instead offered a process that more fully integrates students into the community.

Victoria University has also gone beyond the implementation of restorative justice as a response to discipline issues to begin to create a Restorative University that fosters positive relationships founded on mutual care, respect, responsibility, and honest communication at all levels. This restorative community is being built through the intentional implementation of restorative practices such as circles and the restorative conversation model that build, maintain and repair relationships within the university community throughout the year. The university uses the model of the triangle of restorative practices in order to illustrate the way that these practices build on each other. When more time and energy is spent building positive relationship based on honesty, meaningful connection, and respect, less time will be spent repairing relationships when things go wrong.

Imagine a first year university student experiencing the stress of being away from home for the first time and the pressure of his course load. He goes out for drinks with his friends and returns to his dorm intoxicated. He gets in a fight with his friend and ends up acting out violently, throwing things and striking his friend, drawing the attention of his Residential Advisor. In the past, an assault of this sort would most likely result in, at a minimum, the student being evicted from the Residential Hall. It could be that the financial strain of this loss of housing would result in the student having to take time away from university. Ultimately, the university's response to a mistake brought on by stress, alcohol, and poor coping strategies could cause a great deal more harm in the student's life. The friend who has been harmed would also be left out of the decision-making process and would not have a chance to voice his needs or concerns. The two friends furthermore may not have a chance to repair their relationship and work through the incident to move forward in a positive way. 
Following the implementation of restorative justice, this student instead has the opportunity to sit down and talk with the friend and other impacted parties including the Residential Advisor. With the guidance of a facilitator, the group would discuss what had happened, how each person was impacted, and form and commit to a plan to repair the harms and make things right. This plan may include an apology and actions to improve life in the residential hall for others. It would also include measures to address the stress that led to the incident. Perhaps the student would benefit from regular meetings with the Student Support Coordinator or from being more intentionally involved in social activities in the hall.

Instead of the student being expelled from the community, the people closest to the student would make an extra effort to understand the student's experience, needs, and what can be done next to make things better for all involved.

In order to offer this process to students and staff following incidents of wrongdoing, the university has taken steps to make restorative justice facilitators available on campus. As the number of referrals for restorative justice conferences continued to increase throughout 2016, Residential Life saw a need to form a team of restorative justice facilitators who could be assigned to facilitate cases after they were vetted by the Chair of Restorative Justice staff. In September 2016, the university trained a group of sixteen Victoria University staff members in restorative justice facilitation. The university entered the 2017 school year with the capacity to expand implementation greatly increased. As of 2017, restorative justice is also included in the Student Conduct Statue as the first choice response to student misconduct (Victoria University of Wellington Student Conduct Statute).

The implementation of restorative justice has received positive feedback from both students and staff. One Residential Advisor commented, "Going from a "who needs to be punished" mindset to a "what can we do to repair this and make things right" mindset, I believe, is a clear step to making the world a better place' (Restorative University Training Feedback Questionnaire) ${ }^{1}$. Another Residential Advisor noted that restorative justice 'really placed emphasis on the idea that there may be underlying problems for the issue at hand and working towards a way to solve these issues effectively' (Restorative University Training Feedback Questionnaire). Another Residential Advisor similarly commented on the needs-centred focus of restorative justice saying, 'Considering others' needs and solving issues in a way that places the highest value on meeting others needs and ensuring learning and growth comes from mistakes and the outcomes feels positive for those involved' (Restorative University Training Feedback Questionnaire).

Residential Advisors have also noted that the restorative justice method of problem solving is applicable to other areas of their lives. One noted, '[The restorative justice training] was really useful for not just the work environment but will be useful for other parts of life' (Restorative University Training Feedback Questionnaire).

\footnotetext{
${ }^{1}$ All quotes from feedback questionnaires are shared with the permission of the participants. 


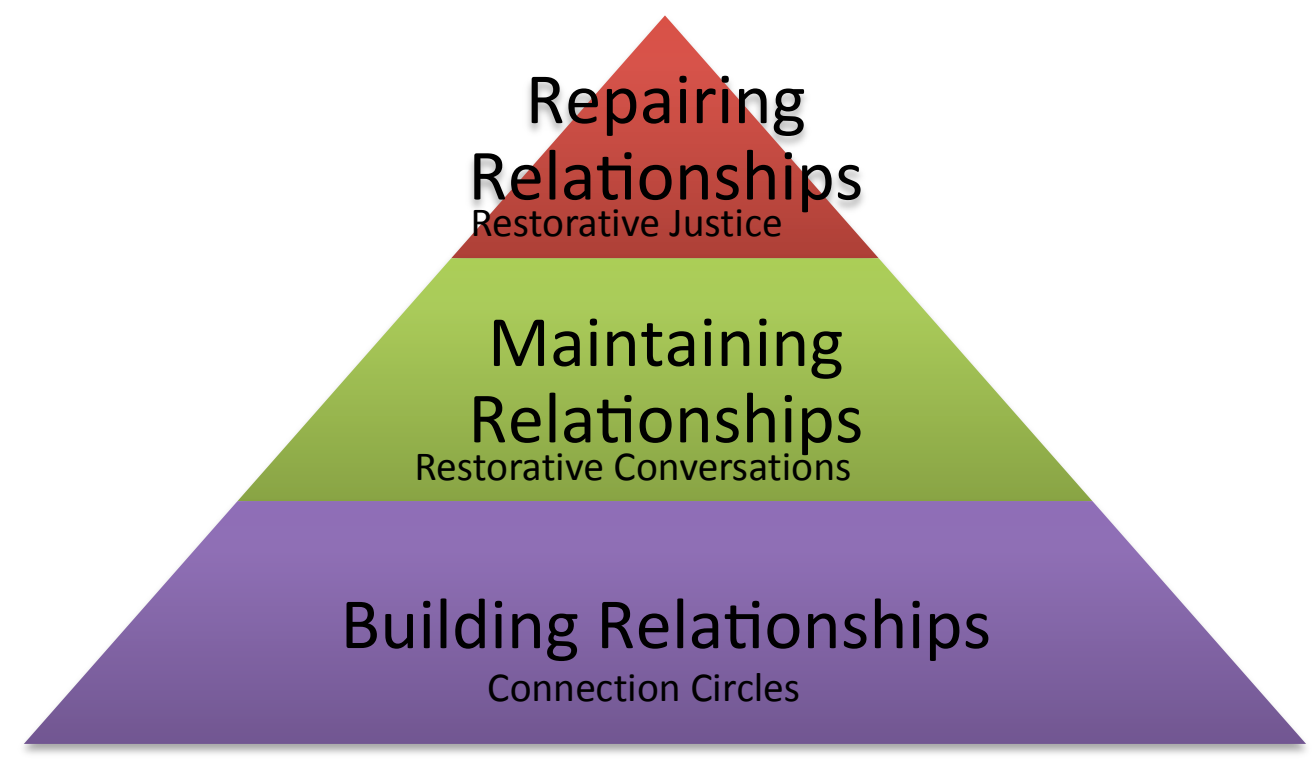

Using restorative justice to respond to issues on campus

\section{Building and maintaining relationships through circle processes and restorative conversations}

Victoria University has also begun an effort to use restorative practices proactively to build a restorative community culture on campus. This proactive effort includes a shared commitment to fostering positive relationships based on respect, empathy, accountability, and belonging. It also includes the intentional implementation of specific restorative tools, namely the connection circle and the restorative conversation model.

The connection circle is a simple but powerful tool for bringing members of a community together to build connection through open, honest sharing and empathetic listening. Open-ended questions encourage deepening levels of sharing as a community moves through the process together. The same circle tool can be used to establish group norms through asking what each member of the community needs in order to thrive in the community. It is also used to respond to conflicts and issues in the community through question rounds following the central restorative questions (What happened? Who was affected? What can be done to make things right?). Connection circle facilitators on campus are trained in how to establish a safe and supportive space to encourage open communication and community cohesion.

The restorative conversation model provides a format for holding difficult conversations one-onone. The restorative framing of the conversation allows those in conflict to move towards greater understanding and resolution. The conversation model is easily implemented in professional relationships as well as in working with students.

This effort to build a Restorative University through proactive community building has been primarily implemented in the Residential Halls. At the beginning of the 2016 and 2017 school years, all Residential Advisors were introduced to the restorative justice approach and were also taught how to use a connection circle model to build relationships among the residents on their floor and establish group norms. The Residential Advisors were also taught how to use the connection circle to respond to group behaviour issues that impact the entire community such as vandalism, messiness and noise.

The training was met with great enthusiasm by the Residential Advisors; $100 \%$ reported being satisfied or very satisfied with the training experience. Residential Advisors also saw the direct 
applicability of restorative practices to their work. One Residential Advisor reported, 'I think restorative conversations and connection circles are going to play a really big role in how my floor works this year to foster community within' (Restorative University Training Feedback Questionnaire).

One Residential Advisor sent the following report after using the connection circle tool with her residents. Note that the connection circle is facilitated using a 'talking piece' so that everyone has an equal opportunity to speak. In this story, she mentions using a pair of scissors as a talking piece.

I held a circle meeting with my floor of residents for our first floor meeting and it was WONDERFUL. After some gentle and funny ice breakers, I introduced the idea and started it off with a pair of scissors that hadn't left my hands for the last week in preparing the decorations for the floor for them. I explained the scissors symbolized my dedication to the floor and the open space I wanted to create for the sharing of ideas and skills. I set the intention of the circle as a discussion of our values/rules that are important to make everyone feel at home. The first few people passed them on without saying much, but once they got talking it was awesome! I was writing them up on a piece of card to keep on the wall and it was things like "Smiling at everyone," "Celebrating peoples' birthdays" as well as rules about cleanliness and noise. Really such a great way to start the year! ${ }^{2}$

Residential Advisors have continued to see the positive results of implementing restorative practices as the year progresses. One Residential Advisor reported, 'We've found that simply talking respectfully and calmly to students in addition to initially establishing group norms has meant the students have responded positively' (Restorative University Training Feedback Questionnaire.)

Connection circle and restorative conversation training has also been offered for Residential Life professional staff. This group has been encouraged to use the process within staff groups, with the Residential Advisors they supervise, and with students living in the halls. Feedback about these techniques was positive as participants began integrating restorative approaches into their life at the university. One training participant noted, 'Building restorative practice both in daily conversations and within Hall communities is extremely important. We need to move away from disciplinary and blame to mending/fixing what is broken' (Restorative University Training Feedback Questionnaire).

Interest in the work being done at Victoria University has also spread to other universities. In October 2016, trainers from Victoria University travelled to the University of Newcastle in Australia to provide a restorative justice facilitator training for members of their staff and to support and advise implementation of the process. The trainers returned in January 2017 to provide training in connection circles and restorative conversations for the University of Newcastle Residential Advisors.

The growth of the Restorative University model is filling a much-needed gap for campus communities. We know that student behaviour, learning, and happiness is rooted in feelings of belonging, in feeling valued as individuals within a connected and supportive community. This feeling of belonging and connection is only accomplished when we devote time and energy to intentionally building, maintaining and repairing relationships. Restorative practices offer concrete tools and a grounding philosophy to build these thriving communities.

\section{Conclusion}

Through the leadership of the Diana Unwin Chair of Restorative Justice and the support and commitment of many others on campus, Victoria University is becoming a Restorative University.

\footnotetext{
${ }^{2}$ Residential Advisor, email message to author, February 29, 2016. Shared with permission from the Residential Advisor. 
As the efforts of Residential Life have progressed, other areas of the university are increasingly climbing on board and beginning to implement restorative practices. The holistic approach to restorative culture change innovated by Victoria University has the potential to be adapted to a wide range of other organisational contexts and represents a promising new development in the field.

\section{Acknowledgement}

I would like to acknowledge Professor Chris Marshall, The Diana Unwin Chair in Restorative Justice, for his tireless efforts in building a restorative culture at Victoria University of Wellington and beyond as well as the numerous other proponents and practitioners throughout the university. 


\section{References}

Boston, J. (2007). Towards a Restorative Society. Restorative justice and practices in New Zealand: Towards a restorative society. Wellington, NZ: Institute of Policy Studies.

Braithwaite, J. \& Strang, H. (2001). Introduction: Restorative Justice and Civil Society. Restorative Justice and civil society. Cambridge, UK: Cambridge University Press.

Diana Unwin Chair in Restorative Justice. Retrieved from http://www.victoria.ac.nz/sog/researchcentres/chair-inrestorative-justice.

Karp, D. \& Sacks, C. (2014). Student conduct, restorative justice, and student development. Contemporary Justice Review, 17(2).

Marshall, C. (2016). The evolution and meaning of the restorative city ideal: An Introductory essay. Unpublished.

Pranis, K. \& Boyes-Watson, C. (2015). Circle forward: Building a Restorative school community. St. Paul, MN: Living Justice Press.

Victoria University of Wellington Student Conduct Statute. Retrieved April 11, 2017, from $\mathrm{http}: / / w w w . v i c t o r i a . a c . n z / d o c u m e n t s /$ policy/student-policy/student-conduct-statute.pdf.

Wachtel, T. \& McCold, P. (2001). Restorative justice in everyday life. Restorative justice and civil society. Cambridge: Cambridge University Press.

\section{The author may be contacted via}

lindseycpointer@gmail.com 